\title{
Outside the Net: Intersectionality and Inequality in the Fisheries of Trincomalee, Sri Lanka
}

\section{Gayathri LOKUGE and Dorothea HILHORST}

\begin{abstract}
Inequality and conflict in Sri Lanka have frequently been analyzed along ethnic lines. However, many scholars have stressed the importance of other dimensions of identity, such as gender, caste and class, in studying social tension. This study uses intersectionality theory to examine how a combination of the social categories of gender, race, ethnicity and location creates structural inequality. This article draws upon in-depth research on Muslim, Tamil, Sinhalese and indigenous/Veder women who catch and market fish in the conflict-affected eastern district of Trincomalee, Sri Lanka. The focus was on intra-group differences among these women and the different sources of power they use to subvert existing power structures. Although multiple inequalities affected the respondents' daily lives and participation in activities, they were not passive victims; they used their own agency to negotiate for their livelihoods. Nevertheless, the women who comprise the focus of this study appeared to be completely invisible to government fisheries management bodies. The lack of institutional representation has disadvantaged them in their negotiations for space to engage in livelihood activities. Registration of these women by the government department of fisheries among those who make a living from fishing would provide them with a first measure of recognition and empowerment, strengthening their chances of negotiating access to the fishery livelihood resources.
\end{abstract}

Keywords: women in fisheries, intersectionality, Sri Lanka, conflict, livelihoods 


\section{Introduction}

Most discourses on conflict in Sri Lanka have emphasised ethnicity (Frerks \& Klem, 2004), masking the social inequalities that emerge at the intersection of gender, caste and class (Silva, Sivapragasam \& Thanges, 2009). Writing in the post-war Sri Lankan context, RajasinghamSenanayaka (2009) drew attention to the need to "look beyond the culturalism or 'ethnic' narrative, and understand the embedded social and economic inequalities" (as cited in Arambewela \& Arambewela, 2010, p. 373). The present study aims to provide a nuanced understanding of power structures that marginalize coastal women in Trincomalee District in Sri Lanka, at the intersection of caste, ethnicity and location and of how they experience, reproduce and resist these power structures in their daily lives.

In general, little is known about women's livelihoods during the war in Sri Lanka. Korf (2004) found evidence of changing gender roles during the conflict in eastern Sri Lanka, reporting that women took on the role of marketing agriculture produce in areas controlled by the Liberation Tigers of Tamil Eelam (the LTTE, which challenged the state for a separate Tamil homeland and suffered a comprehensive military defeat in 2009). However, to the best of our knowledge, there are no studies of women in fishing communities during the war. PereraMubarak's (2012) work on coastal women in this southern part of the country is a rare contribution regarding the post-war period.

The fisheries sector is at the center of post-war reconstruction discussions in Sri Lanka. During times of heightened violence, the fishing industry in the northern and eastern provinces was crippled by loss of equipment, lives and infrastructure, as well as heavy restrictions (Siluvaithasan \& Stokke, 2006). Prior to the violent conflict, the then combined northern and eastern provinces contributed 64 percent of the total Sri Lankan catch of fish, as per records of 
1980 . This dropped dramatically to 20 percent by 2000, before rising to 38.2 percent in 2010 . More significant than the monetary value, the fisheries sector is a major provider of regional employment: in 2012, three districts of the eastern province employed 38 percent of all those engaged in the country's 15 fishing districts, with Trincomalee alone accounting for 14 percent (Department of Fisheries, 2013).

Globally, the discussion on women and fishing is not new and considerable progress has been made to improve their visibility in the industry. For example, in South Asia early reports from the Bay of Bengal project highlights the lack of data to make a strong case for the extent of women's engagement in the fisheries sector $(\mathrm{FAO}, 1980)$. Over the decades, data collection and academic interest in the sector with a gender focus seems to have increased and there is a body of literature on women's involvement in fishing (Weeratunge et al, 2010). One such initiative is the European Network of fisherwomen's organisations (called AKTEA), with eleven members. As of the late 1990s the Asian Fisheries Society and World-fish Centre has initiated a series of dialogues, which have sought to provide evidence that women do fish and they are involved in the fisheries supply chains. They have made a more comprehensive effort to try and understand not only the involvement of women, but also that of men and children in fishing related activities (Choo, Barbara, Novak, Kusakabe \& Williams, 2008).

However, it can be argued that women's contribution to the fishing household economy and the sector as whole is still underestimated or ignored. For example Weeratunge et al. (2010) discuss how gleaning and near-shore fishing and pre- and post-harvest activities such as mending nets, preparing food for fishermen and keeping accounts are under-represented as employment categories. The Big Numbers Project in certain countries is trying to overcome this gap and to 
collect and present data disaggregated by gender (Weeratunge et al., 2010). Of the case study countries, India and Nigeria show high percentages of women engaged in the fisheries sector in fishing apart from the processing and gleaning activities.

Regardless of ethnicity, women were excluded from fishing-related spaces due to cultural taboos regarding gender and institutionalized practices such as the exclusion of women's participation in the sector from management bodies and official statistics. This trend corresponds very clearly with feminist writing on the subject, especially in the use of intersectionality as a lens to explore how women are structurally marginalized (Staunæs, 2003) and how class, ethnicity and regional disparities combine with gender to produce social difference (Bilge, 2010; Collins, 2000; Crenshaw, 1989). In Sri Lanka, in the Eastern Trincomalee district, fishing is associated with men, while women are seen to play an ancillary role. Thus, fishery officials, community leaders and fishermen (all men) dismiss women's involvement in fishery livelihoods. Mostly ignored by policy makers and community leaders, coastal women in Trincomalee engage in marine- and lagoon-based fishing livelihoods, supporting their families, in some cases singlehandedly.

This article focuses predominantly on fisher-women from low socioeconomic groups, engaged in marginal livelihoods, working hard, smelling of the lagoon and fish, and earning a lower income, compared to men. These women belonged to the minority ethnic groups of Muslim, Tamil and Veder (an indigenous community). Through a focus on overlapping marginalities, due to gendered access to livelihood spaces, disadvantages faced due to ethnicity, and to a lesser extent caste, this article adds to the emerging body of studies on intersectionality and how women are structurally marginalized (Staunæs, 2003). It also examines how class, 
ethnicity and regional disparities intersect with gender to produce social difference (Bilge, 2010; Collins, 2000; Crenshaw, 1991). Nevertheless, the story of women in coastal Trincomalee is not one of exclusive and complete marginalization. By bringing in narratives of women's agency, this article points towards the need to re-think the application of the intersectionality lens to capture people's agency and power in greater depth.

On Kinniya beach in Eastern Trincomalee, around 50 women collect seaweed for sale to biscuit and jelly manufacturers outside the district. During the sea-weed season, they earn about 1,000 LKR per day. Most of them wade into shallow waters with a hand net to collect the seaweed; others obtain it from the men who pull the beach seine ${ }^{1}$ nets from the beach, for example, a woman $I^{2}$ talked to walked to the other side of the beach seine, sat down on the sand and started making a pile of the seaweed that the men were taking out and dumping by the side of the net. She didn't touch the seaweed till it was laid on the beach, sorted out by the men (Field observations, 14 November 2013, Kinniya beach).

As our interactions with these women lengthened, I was left with questions such as why do these women not touch the seaweed, a waste product, until it is taken out of the nets? How do custom and tradition stand in their way? Would they be allowed 'inside the net' if the men who operated the beach seines acknowledged their significant contribution to the family income? I asked such questions during fieldwork. This paper is organized into four main sections. First, the conceptual framework introduces and discusses the relevance of intersectionality theory for the analysis. Next, the methods section presents the nature of data collected, the choice of methods, selection of locations and a brief snapshot of the respondents. The results and discussion sections first present women's participation in fishing-related activities in coastal Trincomalee. Next, the paper discusses the following: the use of historical livelihood traditions as in the case of Muslim 
women; inequalities resisted and reproduced, as in the case of the Veder women; and exclusion based on norms, location and lack of a traditional livelihood history in the case of Sinhalese women. The discussion section concludes with a presentation on shared inequalities across different identity groups, followed by a concluding section.

\section{Conceptual Framework}

\section{Women in fisheries}

As a broad generalization, in South Asia, fishing at sea is dominated by men, while the handling, processing and marketing are done by women (Food and Agriculture Organisation [FAO], 1980; Gupta, 2003; Hapke, 2001; Johnson, 2002; Srinath, 1987). Similar patterns are seen in the northwestern and northern Sri Lankan coasts, where female relatives of fisher folk are historically responsible for marketing (Bavinck, 1984), As Stirrat (1988) observed: "Once the fish was out of the net, it became the responsibility of the women to transport it to the market and sell it" (p. 73). However, this practice is looked down upon by middle class Sinhalese women.

Globally, the attention of state fisheries managements is on off-shore and near-shore fishing by men (Jentoft, 1999; Weeratunge et al., 2010; Yodanis, 2000). Fishery management is a relationship between the government and a rights-holder, who is an individual and usually male (Jentoft, 1999). However, a strong body of work has explored women's contribution to the sector, worldwide (Weeratunge et al., 2010; Yodanis 2000). Jentoft (1999) has claimed that women's relatively low participation is one reason for the overwhelming focus on men. Yodanis (2000), however, has argued that women's social position is affected by the fact that they are not 'fishermen,' and the gendered socialization process in fishing villages results in women 
identifying themselves as doing non-fishing work; to be a woman is not to be a fisher(man) (p. 268). The lack of women in management positions in the sector is another reason for their low recognition.

Questions regarding evidence and data become crucial regarding the limited recognition of women in the fishing industry. The primary focus on men's fishing activities across the world means that women's engagement in gleaning ${ }^{3}$ and near-shore work often goes unnoticed. Similarly, pre- and post-harvest activities carried out by women, such as net-mending, providing food, fish processing and marketing are often not enumerated or are underestimated as employment (Weeratunge et al., 2010). Despite awareness on the need to generate better genderdisaggregated data, there is still a gap, which constrains the formulation of more sustainable and efficient decisions and policies (Choo, Barbara, Novak, Kusakabe \& Williams, 2008; Weeratunge et al., 2010). In Sri Lanka, active data on the marine fishing sector is not disaggregated by gender, leading to policies targeted exclusively at men.

\section{Intersectionality and inequality}

The interrelatedness of social divisions, in terms of the production of social relations and their impact on people's lives, has been analyzed over at least two decades (Anthias \& Yuval-Davis, 1992; Collins, 1998). Growing out of black feminist work that criticizes the treatment of gender and race as two separate dimensions of discrimination, intersectionality refers to "the interaction between gender, race and other categories of difference in individual lives, social practices, institutional arrangements and cultural ideologies, and the outcomes of these interactions in terms of power" (Davis, 2008, p. 68). The concept has been used to highlight how certain groups are marginalized (Staunæs, 2003) and to understand how race, class, ethnicity and regional 
disparities combine with gender to produce social difference (Bilge, 2010; Collins, 2000; Crenshaw, 1991).

Theoretically, the concept of intersectionality integrates macro- and micro-sociological analyses. At the macro or structural level, "it questions the ways in which multiple systems of power are involved within the production, organisation and maintenance of inequalities" (Bilge, 2010, p. 60). At the micro-level, it involves the interaction between social categories and sources of power and privilege, as well as how structural inequalities affect individual lives to create unique configurations (Henderson \& Tickamayer, 2009). However, most intersectionality literature stresses macro-processes (Bilge, 2010; Collins, 2000; Staunæs, 2003) and overemphasizes structural inequalities that have compromised the subjective dimensions and the understanding of individual agency and identity formation at the individual level (Long, 2001, Staunæs, 2003, p.103).

However, women's agency, particularly in war affected Sri Lanka is rich and deep. These discussions primarily take two persepectives. First, some work has questioned whether these women undertook non-traditional roles (for example, as household heads and principal breadwinners) during the conflict and may have lost afterwards, as has often been the case historically (Enloe, 1983; Jayawardena, 1986). Second, as argued by Rajasingham-Senanayake (2004), women's agency and the spaces they carved out for themselves may continue after the war. An engagement with this body of work will provide a nuanced understanding of the intersectional analysis. 
A growing body of literature focuses on the impacts of intersectionality on labor or livelihood trajectories (Beneria \& Roldan, 1987; Collins, 2000; Glenn, 1985; Hapke, 2010). Hapke (2001) has used the concept of social location to illustrate the role of what she calls structural contexts (i.e., geographic region and political context) and identity traits (e.g., class, caste, religion, gender, age and family ideology) in shaping the division of labor within two fisher-communities in India. In Sri Lanka, ethnic and gender dimensions dominate livelihood discussions (see Ruwanpura \&Humphries, 2004). Other studies have gone beyond ethnic categorization, bringing in class and geographical location as important elements with gender identity (Hyndman \& de Alwis, 2004). Conflict affects women differently, depending on their religion, caste, class, ethnicity, location, political affiliation and a variety of other overlapping factors (Rajasingham-Senanayake, 2004, p.149). Correspondingly, regarding women's recovery after the 2004 Indian Ocean tsunami, Perera-Mubarak (2012) has stated that the ability to cope with disasters is shaped by gender, ethnicity and location.

Drawing on the narratives of Sinhalese (Buddhist), Tamil (Hindu), Muslim and Veder women in the Trincomalee District, this article attempts to analyze how women experience structural inequalities at the intersection of ethnicity, caste and location. Given that all of the respondents included in this study represent economically and socially marginalized groups, we have chosen to focus on identity categories other than class, unlike most existing empirical work on intersectionality and labor/livelihoods. ${ }^{4}$ The present study aimed to understand how women resist and reproduce structural inequalities using their own agency. 


\section{Methods}

This study is based on empirical material collected during the one year and more of field work in Trincomalee district on the East coast. The district is the epitome of diversity and contradiction: socially, culturally, politically, economically and geographically. It is one of the few districts in Sri Lanka where the three main ethnic groups are represented relatively equally. At present, in terms of demography, Trincomalee's population is 27 percent Sinhalese, 30.6 percent Sri Lankan Tamil, 40.4 percent Sri Lankan Moor and 2 percent other ethnicities (Department of Census and Statistics, 2012). However, this composition is a relatively recent phenomenon, as the area has been a site where "a process of mixing and violent un-mixing of people" has taken place historically (Skinner, 2005, p. 3; Rajasingham, 2000). Therefore, given its multicultural nature, McGilvray (2001, p.1) has argued that Trincomalee " has become pivotal to the island's political future" and that "more than any other part of the country, it is a site for multicultural contestation and alternative ethnic futures."

Comprising 11 Fisheries Inspector Divisions, Trincomalee is one of the largest fishing districts of Sri Lanka, both geographically and in terms of the number of people involved in the industry. As of 2015, Trincomalee reported 33,950 active fishermen (Ministry of Fisheries and Aquatic Resources Development, 2016), of a total of 72,504 employed men (Department of Census and Statistics, 2016). Of all the districts in the country, it is home to the largest number of active fisher-folk (Ministry of Fisheries and Aquatic Development, 2016). Data were collected via observations and informal conversations with approximately 100 women in the lagoon, on the beach, in the market and at home. I also collected in-depth narratives of eight women (three Muslim women, two Tamil women, two Sinhalese women and one Veder woman) during several and repeated visits to their workplaces and homes, during which I had informal conversations 
with them, their family members and co-workers. In addition, I conducted a census of 32 coastal villages along the brackish coastal waters of the district (see Figure 1), profiling women engaged in gleaning, fish selling, prawn and crab catching, and other beach seine-related activities. The data were coded and analyzed using NVivo software.

Figure 1: Map of Trincomalee indicating the location of the research sites 


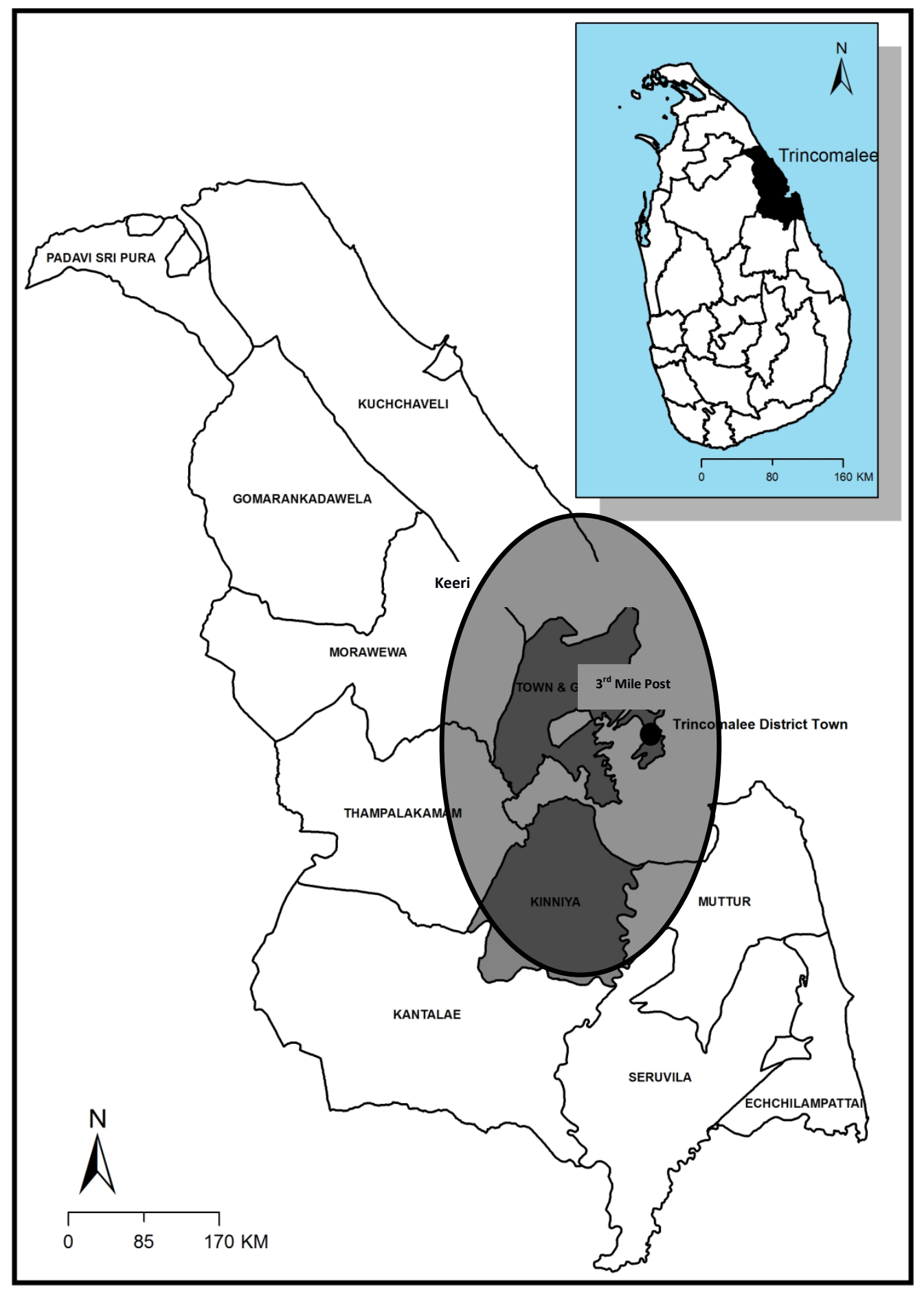


According to the state Ministry of Fisheries and Aquaculture (2016), the women respondents of this study belong to the marine fishing sector, which includes lagoons and brackish water bodies. My specific focus was on groups of women working as gleaners catching prawns and crabs by hand or using basic fishing gear in the lagoons; engaging in sea food retail marketing; and working on beach seines in the shallow seas.

Table 1. Profile of women engaged in fisheries-related livelihoods in Trincomalee District.

\begin{tabular}{|c|c|c|c|}
\hline Name of the community & Ethnicity & $\begin{array}{l}\text { Number of } \\
\text { women }\end{array}$ & Livelihood activities \\
\hline Sampaltheeve & Tamil & 4 & Fish retail \\
\hline Thirukadaloor & $\begin{array}{l}\text { Tamil and } \\
\text { Sinhalese }\end{array}$ & 3 & Fish retail \\
\hline Verugal & Tamil & 25 & Pulling beach seine nets \\
\hline Vellamanal & Muslim & 8 & Gleaning \\
\hline Karadifoul & Tamil & 4 & Gleaning \\
\hline Periyaththumunai & Muslim & 75 & Gleaning \\
\hline Maahaththungar & Muslim & 50 & Gleaning, catching prawns \\
\hline Naduththeevu & Muslim & 20 & Gleaning, catching prawns \\
\hline Soorangal & Muslim & 13 & Gleaning, collecting firewood \\
\hline Sinnakuda & Muslim & 12 & Gleaning \\
\hline Irakkakandy & Muslim & 10 & Gleaning, catching prawns \\
\hline Pudawakattu & Muslim & 40 & Gleaning, collecting firewood, \\
\hline Mathurankuda & Tamil & 15 & $\begin{array}{l}\text { Gleaning, catching prawns, catching crabs, } \\
\text { collecting firewood, performing wage work, }\end{array}$ \\
\hline Salaipaiyaru & Tamil & 50 & $\begin{array}{c}\text { Gleaning, sorting fish from beach seine, } \\
\text { catching prawns }\end{array}$ \\
\hline Periyakulam & Tamil & 6 & Catching prawns \\
\hline Thuvarankadu & Tamil & 10 & Catching prawns \\
\hline Konesapuri & Tamil & 6 & Catching prawns \\
\hline Kappalthurai & Tamil and Muslim & 60 & $\begin{array}{l}\text { Gleaning, catching prawns, catching fish, } \\
\text { catching crabs }\end{array}$ \\
\hline
\end{tabular}




\begin{tabular}{|l|c|c|c|}
\hline Name of the community & Ethnicity & $\begin{array}{c}\text { Number of } \\
\text { women }\end{array}$ & Livelihood activities \\
\hline Muttu Nagar & Muslim & 7 & Gleaning, catching prawns \\
\hline Meera Nagar & Muslim & 14 & Gleaning, catching prawns \\
\hline Kokkilai & Tamil & 30 & Gleaning, catching prawns \\
\hline Solaiyadi & Tamil & 15 & Gleaning, catching prawns, catching crabs, \\
catching fish
\end{tabular}

Source: Primary data collected through a census of coastal communities in Trincomalee District

As Table 1 illustrates, most of the women engaged in gleaning were Muslims. This group also reported collecting seaweed and catching seasonal prawns in the lagoon. All those engaged in beach seine activities were Tamil, either of Indian origin or from the indigenous (Veder) communities. Women of the latter community pulled the seine nets throughout the process, whereas the Indian Tamil women only helped in sorting the fish from the cod-end or the central part of the net. The fish retailers who participated in this study traced their roots back to Jaffna and indicated that they were Sri Lankan Tamils. Another group of sellers encountered were of 
Indian origin. Except for the fish sellers, none of the women belonged to the caste of fisher-folk and, with the exception of two fish retailers, there were no Sinhala Buddhist or Catholic women engaged in any of these livelihood activities.

\section{Results and Discussion}

\section{Ethnicity, settlement patterns and cultural diffusion}

Study findings indicated that Tamils and Muslims along the eastern coastal line of the Trincomalee district traced their ancestry in the region back to at least two or three generations, while the Sinhalese people in the region traced their roots back to only one generation. The pattern of settlements, with ethnic enclaves in close proximity with each other, meant that elements of culture, in the form of norms and rituals, were shared by all three ethnic groups. Muslim and Tamil intermarriage has led to widely diffused cultural practices, except perhaps for caste structures (McGilvray, 1998). The overwhelming presence of Sinhala Buddhist fisher-folk at the Hindu kovil (temple) festivals in Trincomalee, fulfilling vows in the Hindu tradition, are examples of such diffusion in the district (Lokuge \& Munas, 2017). One consequence of cultural diffusion is that women face certain structural inequalities that cut across categories of ethnic and religious identity. In South Asia, women's lack of involvement in fishing is linked to the notion of "pollution" (Gupta, 2003; Thompson, 1985). In Kerala, India, earlier work has reported that in Hindu, Christian and Muslim fishing communities, women are socially stigmatized as 'impure' and 'untouchable' (Gupta, 2003). Within the Sri Lankan Tamil caste system, in contrast with the Sinhalese one, women are strongly associated with notions of ritual purity/impurity (Silva, Siyapragasam \& Thanges, 2009). Observations showed that this idea was prevalent among all three main ethnic groups in the district. 
Both the Sinhalese and the Sri Lankan Tamil caste systems singled out fisher folk as a separate group: the Karawa (Sinhalese) and the Karaiyar (Tamil) castes. In the Sinhalese caste hierarchy, fisher folk occupy a contested mid-level rank (Roberts, 1982). The Tamil Karaiyar caste also occupies a mid-level position in a contested hierarchy, below the Vellala (farmer) caste, temple-based castes and goldsmiths. Traditionally, these people engaged in deep sea fishing, with legends pointing to a royal lineage and a history of warriors and mercenaries at sea (Roberts, 1982; Silva, Siyapragasam \& Thanges, 2009). Although Muslims and Tamils in the East shared many cultural similarities, the caste system was not one of them. As a Muslim fish trader summarized it (personal communication, (August 14, 2014)), "All of us can pray to God together... A rich person will pray with a fisherman next to him. Barbers and washers and all are equal in our religion." However, in practice, when it comes to fisher folk, a class-occupation identity exists. Another Muslim fish trader elaborated (personal communication, (May 22, 2014)) , "This job is a bad-smelling job, but it will always enable us to have cash in our hand."

Historically, the fish trade in Trincomalee has been dominated by Sinhalese men from the southern province. The war served to consolidate the wholesale fish trade further among the Sinhalese traders, who are primarily from the South and who mainly do not belong to the fishing caste, with Muslims acting as middlemen. In the main wholesale fish market in Trincomalee town, suppliers and buyers from all three ethnic groups can be seen. However, all the stalls are owned by Sinhalese men. The ability of all ethnic groups to converse in both Sinhalese and Tamil languages, when it comes to the jargon of the fish trade, enables easy interaction among suppliers and buyers. In contrast, because most landing sites are geographically part of ethnically organized communities, these are more segregated. 
One thing that the markets and the landing sites in Trincomalee have in common is an almost complete lack of engagement by women. In the pre- and early-war periods, there were a few Tamil women traders at the main fish market, when it was a combined retail-wholesale enterprise. However, with the war and the restructuring of the market into an exclusively wholesale one, the women lost their place in it. The following sections focus on the fishing related experiences of women in coastal Trincomalee.

\section{Use of livelihood traditions in fishing related activities: the case of Muslim women}

Gleaning for clams and mussels (matti in Tamil) was traditionally done by lower-income Muslim women in Trincomalee. The majority of them stand in the lagoons, collecting the clams and mussels by hand. The catch is sold locally by the women themselves or through mobile sellers. They have acquired rowing and diving skills to glean in areas of the lagoon that are too deep to be accessed on foot. They also collect seaweed to sell outside the district and catch prawns and sometimes crabs for local sale when they are in season. For gleaning, the women have skills and knowledge passed down through generations. They use their historical association with the livelihood through their maternal ancestry to continue to access this physical and social space. As one woman put it (personal communication, (January 12, 2014)) :

As this is our grandmother's job, [traditional job] we continue it. If we feel like it, we go to work, otherwise don't need to go. Also, we don't have any expenditure when we do this job. We are collectors and also sellers, so we get the full income (Female gleaner, Muslim).

Although daily subsistence needs drive the women into the lagoons, they choose the location and pace that suits them. They exploit the flexibility of the informal sector and its lack of formal structure, making space for themselves in a sphere where it is traditionally denied to most 
women. They are, more or less, in control of their decision to take on work, although the need to meet daily subsistence needs is pivotal in making this decision.

The women have also capitalized on the market demand for clams and mussels, which are collected primarily by Muslim communities in and around Trincomalee town. The clam and mussel retailers-Muslim women and men — have clearly established a space for themselves in marketing these products. As a result, production and marketing activities related to gleaning have become strongly centered on Muslims here, especially for women, with a sizable group of Tamil women also engaging in the work. However, the social stigma and marginalization attached to gleaning in lagoons and marshy areas suggests class divisions at play in wider Muslim society:

People look down upon those who are doing the matti [clam and mussels] collection, as they collect the matti in the mud area. Others say that there will be a mud smell coming from the matti collectors. As we are the poorest people; rich people don't respect us (Female gleaner, Muslim).

While these women have a sense of pride in continuing their traditional livelihood, those who feel they have achieved a higher socioeconomic status prefer to stop getting into the lagoons. In one Muslim community close to Kinniya, a place traditionally associated with gleaning, labor migration to the Persian Gulf countries has become common among the women. On their return, they tend to stop gleaning in the lagoon. One such woman, Sulehaumma, had managed a certain level of social mobility after meeting her second partner while she was working in Oman. Because of him, she was supporting an extended family of six sisters who were also gleaners:

My husband sends me money to help my people here. I explained to him about the people here who survive by matti collection, that they are very poor, so he sends me money to help 
others. When we die, we are not going to take anything with us. He bought me this land, and I have built this basic house. I am going to build another two-storey house nearby to stay with him when he comes here (Female gleaner, Muslim).

Mobility and employment opportunities for Tamil women are markedly different from what Muslim women have access to (Hyndman \& de Alwis, 2004, p.540). The Sinhalese women generally have greater freedom of movement and engagement in the public sphere than the Muslim women (Hyndman \& de Alwis, 2004; Ruwanpura \& Humphries, 2004), who tend to work (paid or unpaid) within their family homes. However, McGilvray (1998) has claimed that poor Muslim women perform weeding or threshing in the paddy fields, bringing home payments either in cash or kind. The findings of the present study are consistent with McGilvray's analysis, showing that those of lower socioeconomic status engage in livelihood activities outside the home.

Inclusion based on caste-mediated kinship patterns: the case of Tamil women

This section focuses on the fish marketing activities of Tamil women. About three months into field work, I stumbled upon a small retail market at the edge of the traditional fishing community of Periyappadu village. ${ }^{5}$ This market was at the end of a road, dividing agricultural-Vellala and fisher-Karaiyar communities. Repeated attempts to understand women's role in fishing activities in Periyappadu yielded little information about their direct involvement, for example, 'Women help with keeping accounts at home.' However, one day a fish dealer from the community casually mentioned that a few women from the community sold fish at a retail market at the edge of the village. Periyappadu also has a medium-scale wholesale fish market, but the norm was that only men could trade in the market. I learned that three of the four women selling fish at the 
small retail market were from the fishing community, and one was from an agricultural community. Both these communities share historical roots linked to the Northern Province, as well as a complex war history. The fishing community claims to be "sudda thamil" (pure Tamil), tracing their roots back to Valvettithurai in the northern province.

In subsequent visits to the market, I met Rani, a woman in her thirties from the fishing community, who was caring for her 12-year-old daughter alone. She had started selling fish only six months ago, while the other two women from the fishing community had been selling fish for over 10 years. Like the Muslim gleaners, Rani's story illustrates how poor women make a living through fishery-related activities. For her, selling fish was much more than just a livelihood, it also signified her economic independence (personal communication, (March 12, 2014)) :

That is Raaki's cooler [ice truck] on the beach. It's my brother who drives it... If I go that way, they will ask me if I want fish to cook. Even if I don't have anything to cook, I will say no. Why should I ask anything from anyone? I want to live with dignity. Even if I am poor, I want to live with dignity (Female fish seller, Tamil).

The ability to support herself and her family on her own income gave Rani the space to decline support from others, if she wished to. This choice to refuse support from her immediate kin contributed to her self-esteem and self-image, following her separations from her husband and her partner and the displacements caused by war and the tsunami. Thereby, she was able to take sole responsibility for her daughter. Her siblings lived close by, but she was not on very good terms with them. Her support system consisted of relatives from her extended family, fellow traders at the market and other business associates such as customers, to whom she turned for financial and emotional sustenance. 
The fish supply to the four retail sellers at this market was based on community/kinship networks; the suppliers were male relatives and friends who brought small amounts of fish for the women to sell at the market. The buyers were all from agricultural communities and the women received a commission of 10 LKR for every 100 LKR worth of fish sales. The suppliers sometimes left the fish with the women to sell, so a certain amount of trust was required between the two. Table 2 illustrates market transactions on a typical day in this market. Generally, Vani had the largest number of suppliers while Rani had the fewest.

Table 2. Number of suppliers and buyers by dealer/seller, 9:30-11:00am on 6 February 2014.

\begin{tabular}{|l|c|c|c|c|}
\hline & Rani & Padma & Vani & Selvi \\
\hline Suppliers & 8 & 7 & 2 & 4 \\
\hline Buyers/consumers & 23 & 25 & 9 & 16 \\
\hline
\end{tabular}

Source: Primary data

Vani, the retailer was from an agricultural community and caste, had started selling fish at this market only one year before I undertook fieldwork here. She had started selling fish because she did not have anyone to support her, and she was living in a small room adjacent to the market building. Generally, she had few suppliers and explained this as follows:

People from Periyappadu don't give me that much fish. They give the fish to those from Periyappadu. The reason for this is because they are from one caste and I am from another caste. It's their people who bring the fish and they give the fish to their people (Female fish seller, Tamil).

From Vani's point of view, her limited supply was due to her and suppliers' different caste 
affiliations. During the lean fish season, she felt this exclusion even more as whatever was available would go to the three Periyappadu women. Regardless of ethnicity or caste, women are left out of the wholesale fish markets. However, structural inequality is further manifested through the caste axes, affecting women's opportunities to obtain a steady supply of fish to sell at the retail market.

\section{Inequalities resisted and reproduced: the case of the Veder women}

At the southern border of Trincomalee District, I met a group of around 25 Veder women working on the beach seines. I did not find any instances of women pulling beach seine nets in any other parts of the country. Consequently, I followed these women closely. In the general context of coastal Trincomalee, where most people considered that if a woman touched a boat, it would bring misfortune, I was keenly interested in how the Veder women managed to work alongside the men. These women dragged in the beach seine net, side-by-side with the men. The latter always set the net, using a canoe and one woman mended the net just like the men usually did.

The unique character of this group of women was their involvement right from the point when the net was set until the catch landed ashore, working alongside the men, a phenomenon unreported elsewhere in Sri Lanka. Women commonly helped to pull in only the last part of the beach seine (cod-end or madiya) in parts of Trincomalee and on the Northwestern coast of Sri Lanka. However, there is no documented or anecdotal evidence from anywhere else in the country of women pulling in the complete beach seine, as these Veder women did. They also engaged in forest-based livelihoods, such as cutting rattan, collecting wild fruits, fishing in ponds and cultivating chena $^{6}$ and paddy. 
Dart (1990) has argued that coastal Veder people can be primarily defined by their marginality, in terms of both socioeconomic conditions and geographic location. They consider themselves a separate caste group, a perception shared by those outside the community as well, but their position within the Hindu Tamil or Sinhalese caste systems was blurred (Dart, 1990). This contributed to their marginal status. Nevertheless, their distinctive cultural practices and 'marginality' have provided them with certain opportunities. Beach seines are governed by rules and regulations, given in Gazette 337/48 of 21 February 1985, which specifies the type of craft to be used and the use of the beach and the adjacent sea area. Beach seine licenses must be renewed annually and the craft used to set the net must be licensed. However, the beach seines that employ women are not licensed. The owners have acquired 'permission' from the Divisional Secretariat and the local fishing authorities to operate these on the condition that that they refrain from using motorized boats to set the net. In a sense, the beach seines where these Veder (indigenous) women work are marginal to Trincomalee's fisheries sector. Further, they are outside the caste hierarchies of the area and denied any caste affiliation, referring to themselves first as "Veder" and then as Tamil. Not identifying themselves as primarily Tamil/Hindu and being outside the local caste systems meant that these indigenous people did not adhere to the notions of 'pollution' associated with women. In fact, they seemed completely oblivious about it (personal communication, (April 2, 2014)) :

Q: In some places, people say that women touching the net is not good. Is there anything like that here?

A: There isn't any problem like that here, because all of us are related.

(Female beach seine worker, Veder). 
As noted above, one of these women's main strategies for accessing fishing livelihoods is the use of kinship networks. The relative isolation and distinct culture of this indigenous community have led to close or loose kinship patterns. Kaaliaachchi, a female worker around whom Figure 2 is based, is a typical middle-aged woman; her position among her co-workers in the beach seine clearly illustrated the link between her livelihood and kinship patterns. As Figure 2 illustrates, all six women were related to each other and to the men working in the beach seine. However, women faced certain costs in being part of this kinship network. To ensure inclusion in the beach seine activities, women take on expected gendered roles. The overlap of their kinship and occupational networks meant that the gendered roles associated with the private/family sphere extend into the public/work sphere. It is always the women who cook at the beach seine waadi (hut), fetch water and collect firewood. It is always the men who row the canoe. If no men are present, the beach seine does not operate. The women expressed fear of getting into the canoes, and all of them denied ever having been in a canoe. The Veder women, despite overcoming certain limitations, were still acutely conscious of the gendered expectations of their male kin and sought to avoid the outcomes of failing to meet these expectations. The following discussion took place on a day when the beach seine net was not set up because of the temporary labor migration of the men. Adjacent to their beach seine waadi was a beach seine operated by a group of Sinhalese migrant fishermen from the North-western coast. When asked whether they would consider working there, the Veder women responded as follows (April 2, 2014)) :

As we are women, while we work in this [Veder beach seine] waadi, if we go to that [Sinhalese migrant beach seine] waadi, what will this waadi people [Veder kin] say [...] (Female beach seine worker, Veder). 
They were also bound by their responsibilities in the care economy, which sometimes included obligations to extended family. As one woman explained, they cannot travel far outside the community, for example, to Kuchchaveli to work in the Tamil-owned beach seines that allowed women to sort fish from the nets, because that would mean going too far from their families.

Figure 2. Kinship network mapping of a female worker (Kaaliaachchi) in her beach seine.

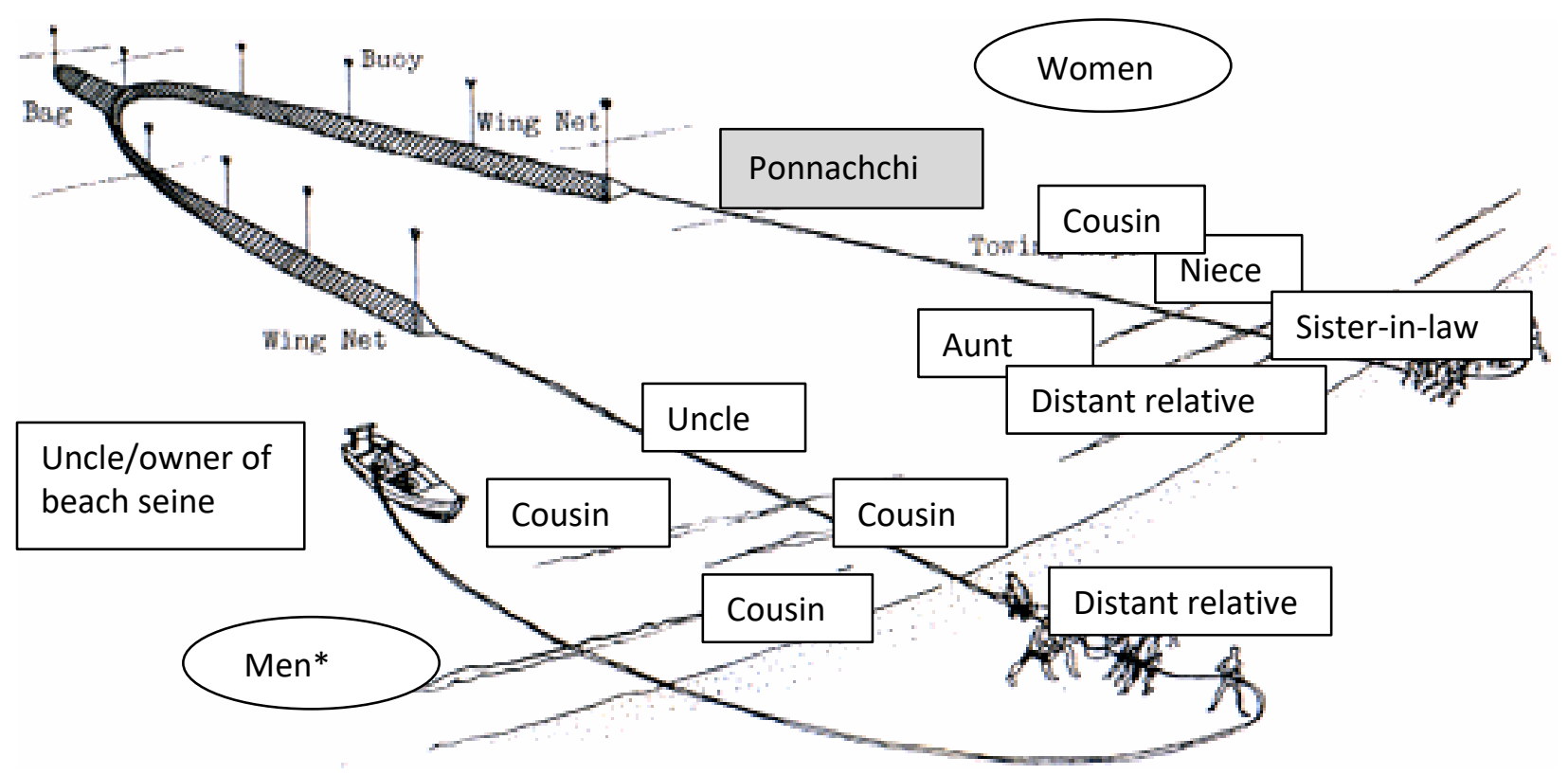

*The women are all on one side, because the men are usually in the boat setting up the net before they start pulling it in. The women hold onto the ropes on the right side of the net, the end that is set first, and leave the left side for the men to pull. We also witnessed women pulling the net together with men on occasions when there was a smaller number of women to pull in the net.

Structural inequalities continued to be reproduced in this setting. Payments were made on a share-based system, wherein the women working in the beach seines were paid less than the men. If the men were paid 1,300 LKR, the women received 1,000 LKR. My study respondents justified this difference, citing the different levels of skill and physical labor required. However, 
the Veder women drew upon their long experiences of engaging in this livelihood activity to ensure income generation without jeopardising their community/kinship allegiances. When the beach seine net was not set up, rather than working on neighboring beach seine, they sought alternative work close by, such as in other types of fishing, agriculture or forest-based work.

Exclusion based on norms, location and lack of traditional livelihood history: the case of Sinhalese coastal women

Research from the early 1980s reported that Sinhalese women were engaged in beach seine activities in Northwest Sri Lanka (FAO, 1980). These women also owned beach seine shares in certain southern coastal areas, although the Sinhalese Karawa caste women seldom engaged in fishing activities actively, instead handing over de facto ownership to male relatives (Alexander, 1977). However, this study of coastal women in Eastern Trincomalee saw a complete lack of involvement by Sinhalese women in fishing-related activities in the past and at present. Given that the permanent settlement of Sinhalese people in coastal Trincomalee can be traced back only to one generation, the term 'past' means a maximum of about 50 years.

Sinhalese women and men in the area looked down upon women (both Sinhalese and others) who went to the wella (beach) on the Northwest coast. Sinhalese men in Trincomalee felt they needed to guard women's virtue, which is tied to men's individual standing and family reputation. This sentiment resulted in the need to control women's dealings with men engaged in fishing. Consequently, the division of labor in most of the Sinhalese fishing households was one where men were fully responsible for all the fishing-related work while the women took care of their households. This yielded a case of clear separation between the private and public spheres. 
The sentiments expressed in the following statement were echoed by many Sinhalese men I met during fieldwork (personal communication, (March 5, 2014)) :

In Negombo, there are women who are involved in fishing. But not here. My wife doesn't even know what color my boat is. We finish settling the money here and go home. I don't leave any dealings with the men to her. I keep some money for my own expenses and give her all the money. She manages all the household expenses. I manage this business (Male fisher, Sinhalese).

Coastal Sinhalese women's lack of access to fishing livelihoods was marked by social norms influenced by historical and demographic factors. Coupled with the security threats faced during the war, the need to guard women against 'enemy invasion' may have contributed to the practice of maintaining distinct private and public spheres. The relatively short period of time that the Sinhalese have lived in coastal Trincomalee, amidst the violence of the war, may have resulted in cultural and social norms that bar women from entering fishing spaces.

Some authors have argued that, although women are systematically more marginalized than men, regardless of ethnicity, in certain instances Sinhalese women are better off with respect to mobility and being less prone to displacement, compared to working class men from the minority groups (Hyndman \& de Alwis, 2004). However, our analysis indicates that the case of Sinhalese women in coastal Trincomalee is different. Their lack of a deep cultural history in Trincomalee influences the involvement of Sinhalese women in fishing-related activities. The 'guardianship' of Sinhalese women has strong resonance with work on ethno-nationalist discourses by feminist scholars, who describe women as bearers of tradition or as cultural representatives (Chatterjee, 1989; Jayawardena \& de Alwis, 1996). 


\section{Cultural melting pot and shared inequalities}

Although the caste system and the Hindu notion of 'impurity' are not part of her religious traditions, a young Muslim woman succinctly summarized her lack of motivation to get involved in the fisheries sector (personal communication, (October 26, 2014)) :

Q: Have you been to sea by boat?

A: People will not take the girls in the beach seine vallam [boat]. They don't allow the women to touch the boat even. They say that there won't be a fish catch. They say it will bring "tharthiriyam" [misfortune]. Small girls are allowed to touch the boats but not young and married women. Once my elder brother scolded me when I touched the boat and after that I don't touch the boat (Daughter of female gleaner, Muslim).

Women are not only considered impure; they are associated with misfortune. Because fishing is an activity that is greatly dependent on chance, social norms and beliefs about fortune and luck play a critical role. Although people did not express these overtly, they suggested them, with the exception of the indigenous women, who were part of a community that did not consider them impure or the cause of misfortune.

In sum, although structural inequalities are manifested at the intersection of gender, location, caste and ethnicity, certain inequalities cut across these categories in Trincomalee, along with cultural diffusion due to generations of co-existence. Therefore, while women experienced varying degrees and types of inequalities at the intersection of the multiple identity categories, the sharing of cultural norms has often implied that, regardless of other identity categories, gender inequalities become decisive factors in the differential access to livelihood resources and opportunities. 


\section{Fishery-related institutions and coastal women's experiences of inequality}

In Sri Lanka, the Department of Fisheries is responsible for management at the district level and for collating data. The latest data on inland fisheries are presented, disaggregated by gender. However, it was seen that data on the marine sector were shown with a single category for "active fishermen and women." Additionally, pre- and post-harvest activities were not considered part of the fisheries sector by the state management bodies. A possible explanation for the lack of disaggregation in the presentation of active marine fishing data in Sri Lanka is the relatively small number of women engaged in these activities. The difficulty in categorizing these women as fisherwomen also relates to the fact that they engage in multiple livelihoods (gleaning and catching prawns, crabs and fish in the lagoons) as a means of weathering seasonality shocks. This makes it difficult to capture them within an institutional definition of fish producers and results in women being left out of the official statistics and typologies.

Moreover, neither the community nor the women themselves acknowledged the role of the latter in catching fish. Most of the women studied identified themselves as gleaners or collectors, while none of them identified themselves explicitly as fisherwomen. They generally lack representation at decision-making levels, for example, just a few women from a few coastal communities mentioned that they were members of the fisheries' societies, but they did not have the identity cards that were issued to male members.

The military is another institution that plays an important role in fishing in coastal Trincomalee. The navy continues to regulate illegal fishing and maintains military outposts in coastal and lagoon locations deemed important for strategic security. The findings from the present study revealed that Muslim, Tamil and Sinhala fishermen negotiate for space to fish in certain areas by providing naval representatives with a part of the catch. Both Muslim and Tamil 
women expressed the need to negotiate with the military to access certain forest areas and lagoons. The Muslim respondents in this study, in particular, reportedly felt apprehensive about engaging in their livelihood with the military nearby (personal communication, (November 4 , 2013)) :

Since last Friday we haven't gone to the forest for any purpose, because the Navy has come to the forest. We don't know the reason why they are there. We are scared to go now. They are bad people, and women can't trust them (Female gleaner, Muslim).

The lack of official recognition of women as part of the fisheries sector disadvantages them in their negotiations with the military and police. After a young man drowned in the adjacent seas, the navy banned a group of about nine Muslim women who collected clams in the shallow seas off Trincomalee from using their vallam (non-mechanized craft) for gleaning. Women, who are not part of a fisheries society, must negotiate with the navy at the naval base in Sinhalese, which is not their first language. They negotiate as a group and through their male kin, but they lack institutional recognition/representation, therefore, the power imbalance becomes more marked. A group of Tamil women who gleaned close to Thambalaguwa, explained to us how they were arrested by the police for damaging the mangroves, which they felt could have been prevented if they had identification documents that stated they were engaging in fishery related activities. Being recognized as part of a community, state recognized bodies such as the fisheries societies need to provide these women with the social and political capital to negotiate with the navy and police.

The lack of gender-disaggregated data makes women invisible to state fishery management institutions, excludes them from receiving state assistance, and leads to inefficient 
management. For example, the state sponsored revolving micro-credit programs that target women in fishing communities address the wives of active fishermen registered with the department of fisheries and excludes the women who engage in gleaning or post-harvest activities. Further, awareness programs on coastal conservation also do not include the women who glean as important actors in the lagoons of Trincomalee.

\section{Conclusions}

Women, regardless of ethnicity, were excluded from fishing-related spaces based on gendered cultural taboos and institutionalized practices such as their exclusion from the management bodies and official statistics. This trend corresponds very clearly with what feminist writers who deploy theories of intersectionality to explore how women are structurally marginalized (Staunæs, 2003) and how class, ethnicity and regional disparities combine with gender to produce social difference (Bilge, 2010; Collins, 2000; Crenshaw, 1991). Nevertheless, the story of women in coastal Trincomalee is not one of exclusive and complete marginalization, and this warrants re-thinking of the application of the intersectionality lens to capture their agentive power in greater detail.

The coastal women in Trincomalee present a bricolage of stories of agency, power and negotiation as they have experienced, resisted and reproduced structural inequalities. Their experiences have constantly shifted over time and space. Historic factors such as population movements and war have shaped the current realities and positions of women. A clear case can be made regarding the specific disadvantages experienced by certain groups of women due to the intersection of ethnicity, caste and livelihood location. Nonetheless, the sharing of cultural norms 
about gender across ethnic lines means that the inequalities they face may overshadow other identities.

Certain historical associations linked to ethnicity exclude women from participation in fishing livelihoods. However, there are counter-examples: norms and tradition enable poor Muslim women to continue gleaning, precisely because they have done so for generations. These women, therefore, are not merely passive, rather, they exercise their own agency. While certain groups of women are at times disadvantaged by the intersection of ethnicity, location and caste, these same categories can provide them with more or less room for manoeuvre to exercise their agency. Kinship networks clearly enable women to negotiate with the military as in the case of Muslim gleaners and social norms as in the case of Veder women. At times, certain groups, such as the latter, drew power from their marginality itself and from the established caste system to transcend gendered labor boundaries. In other instances, Muslim women negotiated for space in the lagoon by forming groups or by negotiating through their male kin.

Despite the end of the war, the military remains part of the institutional landscape of coastal Trincomalee. The continued military presence and the need to interact with its authorities to access livelihood resources marks an ongoing scenario of militarized governance. This context affects power asymmetries, which the women navigate by using different strategies. In designing reconstruction initiatives, decision makers would do well to acknowledge these asymmetries and the lingering effects of the war.

Women engaged in fishing in Trincomalee District employ a diverse livelihood portfolio to manage their daily subsistence and long-term financial stability. However, the very multiplicity in their means of livelihood and their unremunerated contribution to pre- and post- 
harvest activities raises the question about what is recognized as 'livelihood' or 'employment' by policy- and decision-makers. The nature of women's engagement in fishing activities in Trincomalee generally does not require registration of fishing equipment or craft. Therefore, they have no contractual agreements with state fisheries management institutions and are invisible to the government authorities. This means that they are not part of the various livelihood support programs that target coastal women, nor are they part of the fishery conservation programs. Moreover, these women lack formal membership in community fishery societies. Given that they are from lower socioeconomic groups, their non-recognition by state or other institutions renders them even more vulnerable to losing their means of livelihood. Registering women engaged in such economic work would comprise a first measure of recognition and representation and provide a more even playing field for them to negotiate for and gain access to livelihood resources.

\section{Acknowledgements}

Authors are grateful for the financial support provided by the Secure Livelihoods Research Consortium. 
Notes

${ }^{1} \mathrm{~A}$ beach seine is a fishing net deployed from the beach that hangs vertically in the water with its bottom edge held down by weights and its top edge buoyed by floats. A group of fishermen set and pull the net. The number of fishermen required varies

${ }^{2}$ The data collection for this paper formed part of the doctoral research of the first author, who undertook the field work as well. Therefore, in discussions on data collection, the first person 'I' is used, especially in describing interaction with informants in the field. The contribution of the second author was in the research design, analysis and the theoretical framing of the paper.

${ }^{3}$ Collecting clams or mussels in the lagoon areas, usually using their hands.

4. See, for example, Glenn 1985; Beneria and Roldon 1987; Zavella 1991 and Hapke 2001.

${ }^{5}$ Names of villages have been changed to ensure anonymity.

${ }^{6}$ Chena cultivation is also known as shifting cultivation, and it involves the clearing of either primeval or second growth of jungle land every year for cultivation of dry-land products such as grains or certain types of vegetables, for consumption and commercial purposes.

\section{Notes on Contributors}

Gayathri Lokuge is a PhD candidate at the Wageningen University-the Netherlands and a Senior Researcher at the Centre for Poverty Analysis, Colombo-Sri Lanka. Her main research interests include conflict, livelihoods, poverty and identity. Email: gayathri@cepa.lk

Dorothea Hilhorst is a Professor at the International Institute of Social Studies in the Netherlands. Her main research interests include humanitarian aid, disaster studies and gender. Email: thea.hilhorst@wur.nl

\section{References}


Alexander, P. (1977). Sea Tenure in Southern Sri Lanka. Ethnology, 16(3), 231-251.

Anthias, F. \& Yuval-Davis, N. (1992). Racialized boundaries: Race, nation, gender, colour and class in the anti-racist struggle. New York: Routledge.

Arambewela, N., \& Arambewela, R. (2010). Post-war opportunities for peace in Sri Lanka: An ongoing challenge? Global Change, Peace \& Security, 22(3), 365-375.

Bavinck, M. (1984). Small fry: The Economy of petty fishermen in Northern Sri Lanka. Amsterdam: Free University Press.

Beneria, L. \& Roldan, M. (1987). The crossroads of class and gender: Industrial homework, subcontracting, and household dynamics in Mexico City. Chicago: University of Chicago Press.

Bilge, S. (2010). Recent feminist outlooks on intersectionality. Diogenes, 57(1), 58-72.

Bremner, F. (2013). Recasting caste: War, displacement and transformations. International Journal of Ethnic \& Social Studies, 2(1), 31-56.

Chatterjee, P. (1989). The nationalist resolution of the women's question.” In Sangari K., \& Vaid, S. (Eds.), Recasting women: Essays in colonial history, (pp. 233-253). New Delhi: Kali for Women.

Choo, P., Barbara, S. K., Novak, Kusakabe, B. S., \& M. J., Williams. (2008). Guest editorial: Gender and fisheries. Development, 51(2), 176-179.

Collins, P. (1998). Fighting words: Black women and the search for justice. Minneapolis: University of Minnesota Press. 
Collins, P. (2000). Black feminist thought: Knowledge, consciousness, and the politics of empowerment. New York: Routledge.

Crenshaw, K. (1991). Mapping the margins: Intersectionality, identity politics, and violence against women of color. Stanford Law Review, 43(124), 1241-1299.

Dart, J. (1990). The Coast Veddas: Dimensions of marginality. In Dharmadasa, K. N. O., \& Samarasinghe, S. W. (Eds). The vanishing aborigines. Sri Lanka's Veddas in transition. Colombo: International Centre for Ethnic Studies.

Davis, K. (2008). Intersectionality as buzzword: A sociology of science perspective on what makes a feminist theory successful. Feminist Theory, 9(1), 67-85.

DCS (Department of Census and Statistics). 2012. Census of population and housing 2012: Provisional information based on $5 \%$ sample. http://www.statistics.gov.lk/PopHouSat/CPH2011/Pages/Activities/Reports/CPH_2012_5 Per_Rpt.pdf

Department of Fisheries and Aquatic Resources. 2013. http://www.fisheriesdept.gov.lk/

Enloe, C. (1983). Does Khaki become you? The militarization of women's lives. London: South End Press.

FAO (Food and Agriculture Organization). (1980). Role of women in the small-scale fisheries of the Bay of Bengal. Madras, India: FAO.

Frerks, G. \& Klem, B. (Eds). (2004). Dealing with diversity: Sri Lankan discourses on peace and conflict, The Hague: Netherlands Institute of International Relations 'Clingendael'.

Glenn, E. (1985). Racial ethnic women's labor: The intersection of race, gender and class pppression. Review of Radical Political Economics, 17(3), 86-108. 
Goodhand, J., \& Klem, B. (2005). Aid, conflict, and peacebuilding in Sri Lanka, 2000-2005. Colombo: Asia Foundation.

Gupta, R. (2003). Changing courses: A comparative analysis of ethnographies of maritime communities in South Asia. MAST, 2(2), 21-38.

Hapke, H. M. (2001). Gender, work, and household survival in South Indian fishing communities: A preliminary analysis. The Professional Geographer 53(3), 313-331.

Henderson, D., \& Tickamayer, A. (2009). The intersection of poverty discourses: Race, class, culture and gender. In Bonny D., \& Zambana, R. (Eds.), Emerging intersections: Race, class and gender in theory, policy and practice (pp.73-100). New Brunswick, NJ: Rutgers University Press.

Hyndman, J., \& de Alwis, M. (2004). Bodies, shrines, and roads: Violence, (im)mobility and displacement in Sri Lanka. Gender, Place and Culture, 11(4), 535-557.

Jayawardena, K. (1986). Feminism and nationalism in the third world. London: Zed Books.

Jayawardena, K., \& de Alwis M. (1996). Introduction. In K. Jayawardena, \&de Alwis, M., (Eds.), Embodied violence: Communalising women's sexuality in South Asia, ix-xxiv. New Delhi: Kali for Women.

Jentoft, S. (2000). Legitimacy and disappointment in fisheries management. Marine Policy, 24(2), 141-148.

Johnson, D. (2002). Emptying the sea of wealth: Globalisation and the Gujrat fishery, 19501999. (Unpublished doctoral dissertation). University of Guelph, Ontario.

Korf, B. (2004). War, livelihoods and vulnerability in Sri Lanka. Development and Change, $35(2), 275-295$. 
Lokuge, G. \& Munas, M. (2017). Risk, reciprocity and solidarity: The moral economy of fishing in Trincomalee, Sri Lanka. In Johnson, D., Acott, T., Stacey, N., Urquhart, J., (Eds.), Social Wellbeing and the Values of Small-Scale Fisheries (pp. 243-265). Birkhäuser Verlag, Springer.

Long, N. (2001). Development sociology: Actor perspectives. London: Routledge

McCall, L. (2005). The complexity of intersectionality. Signs: Journal of Women in Culture and Society, 30(3), 1771-1800.

McGilvray, D. B. (1998). Arabs, moors and Muslims: Sri Lankan Muslim ethnicity in regional perspective. Contributions to Indian Sociology, 32(2), 433-483.

McGilvray, D (2001) 'Tamil and Muslim Identities in the East' in A History of Ethnic Conflict in Sri Lanka: Reconciliation, Reinterpretation \& Reconciliation Marga Monograph Series No. 24 (Colombo: Marga Institute).

McGilvray, D. B. (2008). Crucible of conflict: Tamil and Muslim society on the East Coast of Sri Lanka. Durham, NC: Duke University Press.

Ministry of Fisheries and Aquatic Resources Development. (2016). Fisheries Statistics. http://www.fisheries.gov.lk/content.php?cnid=ststc (Accessed 17 January 2017).

Perera-Mubarak, K. N. (2012). Positive responses, uneven experiences: Intersections of gender, ethnicity, and location in post-tsunami Sri Lanka. Gender, Place \& Culture, 20(5), 664 685.

Rajasingham-Senanayake, D. (2004). Between reality and representation women's agency in war and post-conflict Sri Lanka. Cultural Dynamics, 16(2-3), 141-168. 
Roberts, M. (1982). Caste conflict and elite formation: The rise of a Karāva elite in Sri Lanka. London: Cambridge University Press.

Ruwanpura, K. N, \& J. Humphries. (2004). Mundane heroines: Conflict, ethnicity, gender and female-headship in Eastern Sri Lanka. Feminist Economics, 10(2), 173-205.

Siluvaithasan, A., \& Stokke, K. (2006). Fisheries under fire: Impacts of war and challenges of reconstruction and development in Jaffna fisheries, Sri Lanka. Norwegian Journal of Geography, 60(3), 240-248.

Silva, N. (Ed). (2002). The hybrid island. London: Zed Books.

Silva, K. T., Sivapragasam, P.P., \& Thanges, P. (Eds). (2009). Casteless or caste-blind? Dynamics of concealed caste discrimination, social exclusion, and protest in Sri Lanka. Colombo: Kumaran Book House.

Skinner, J. (2005). The people in-between: Inter-ethnic relations amongst the displaced in Trincomalee District, Sri Lanka. Colombo: International Centre for Ethnic Studies.

Srinath, K. (1987). Role of women in small scale fisheries: A case study. Marine Fisheries Information Service, Technical and Extension Series, 72, 12-17.

Staunæs, D. (2003). Where have all the subjects gone? Bringing together the concepts of intersectionality and subjectification. NORA: Nordic Journal of Women's Studies, 11 (2), $101-110$.

Stirrat, R. L. (1988). On the Beach: Fishermen, Fishwives and Fish Traders in Post-Colonial Sri Lanka. New Delhi: Hindustan Press.

Thompson, P. (1985). Women in the fishing: The roots of power between the sexes. Comparative Studies in Society and History, 27(1), 3-32. 
Weeratunge, N., Bene, C., Siriwardane, R., Charles, A., Johnson, D., Allison, E. H., Prateep, N. \& Marie-Caroline, B. (2014). Small-scale fisheries through the wellbeing lens. Fish and Fisheries, 15(2), 255-279.

Yodanis, C. L., (2000). Constructing gender and occupational segregation: A study of women and work in fishing communities. Qualitative Sociology, 23(3), 267-290.

Zavella, P. (1991). Mujeres in factories: Race and class perspectives on women, work, and family. In M. di Leonardo (Ed.), Gender at the crossroads of knowledge.Berkeley: University of California Press. 